\title{
VIVIR LA UCI: DIFERENTES PERSPECTIVAS
}

\author{
Rubio Rico, Lourdes*; Aguarón García, Maria Jesús**; \\ Ferrater Cubells, María**; Toda Savall, Dolors***.
}

*Profesora asociada del Departamento de Enfermería de la Universidad Rovira i Virgili de Tarragona y enfermera de UCl del Hospital Universitari de Tarragona Joan XXIIII.

**Profesora titular del Departamento de Enfermería de la Universidad Rovira i Virgili de Tarragona.

***Enfermera de UCI del Hospital Universitari de Tarragona Joan XXIII.

e-mail: Irubio@campus.uoc.edu

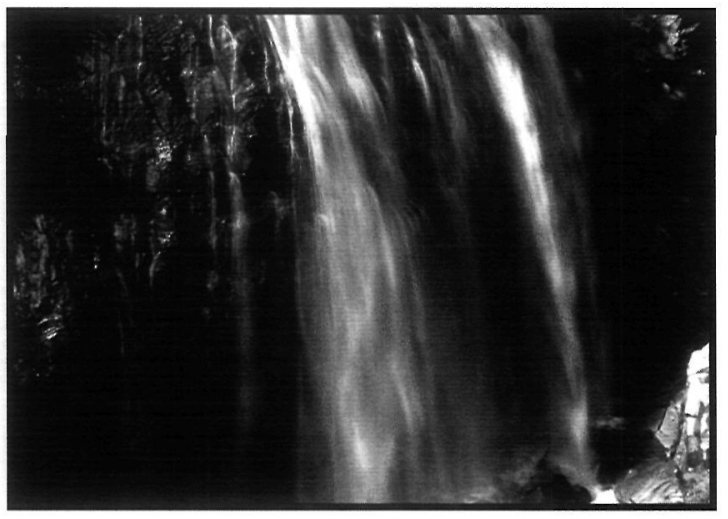

ABSTRACT

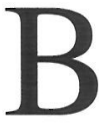
eing in an Intensive Care Unit may become a unique and often distressing experience for patines, relatives and professionals. This work aims to examine different people's experience in ICU and compiles statements from a patient, a relative and two nurses - one of which also offers another perspective from a relative who is a health professional too- in order to analyse the various experiences and identify common and different points. It intends to show the same fact affects people in different ways, harmonise the different versions and use these statements to improve identified deficencies and relieve the pressure of this experience.

\section{RESUMEN}

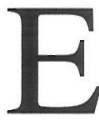

1 paso por una UCI constituye una experiencia singular, a menudo traumática, en la vida de las personas implicadas: enfermos, familias y personal sanitario. El presente trabajo intenta desgranar la experiencia de diferentes personas que, de una o otra manera, han pasado por una UCI y recoge los testimonios de un enfermo, un familiar, y dos enfermeras, una de las cuales aporta también la visión del familiar que es también profesional sanitario, a fin de analizar las diferentes experiencias y buscar puntos de contacto y divergencias entre ellos. Se trata de descubrir como un mismo hecho afecta de diferente manera a los diversos implicados y tratar de conciliar, tanto como sea posible, las diferentes versiones con el fin de utilizar en la práctica este testimonio para mejorar las deficiencias detectadas y aliviar la intensidad de la experiencia.

\section{INTRODUCCIÓN}

Nuestro experiencia como profesionales de enfermería en una UCI nos obliga a situarnos en la ambivalencia. Por una parte nos consideramos privilegiadas por el hecho de poder trabajar en un servicio que por su complejidad humana y técnica nos plantea un reto constante en nuestro trabajo que nos obliga continuamente a formarnos y a ser creativos; también se trata de una unidad dónde la dotación de personal y material, incluso en tiempos de crisis económica de la sanidad y de cuestionamiento de los tradicionales valores de la sanidad pública, es notablemente mejor que la del resto de servicios, lo cual nos permite trabajar en unas condiciones óptimas, sin tener que hacer concesiones a la calidad y finalmente, aún admitiendo que habrá aspectos que escapen a la presente valoración, hacer mención al trabajo en equipo desarrollado efectivamente y a la motivación profesional que genera el trabajo en un ambiente constante- 
mente cambiante y continuamente sometido a nuevas incorporaciones técnicas. Por otra parte, el contacto intenso y continuado con la muerte y el sufrimiento humano que comporta el trabajo en una unidad de enfermos críticos, el trabajo en un medio ambiente con notable presencia de estresores ambientales y la necesidad de incorporar las constantes innovaciones técnicas -factor éste que actuaba positivamente como motivador profesional- hacen de la unidad de cuidados intensivos un servicio altamente estresante, identificado a su vez como factor de riesgo para el padecimiento del síndrome del "born-out".

Esta doble consideración de nuestro trabajo en UCI nos obliga a pensar en la necesidad de mejorar, para todas aquellas personas que de una u otra forma se ven obligados a pasar por ello, las condiciones que acompañan al ingreso en una Unidad de Cuidados Intensivos. El paso previo a esta mejora requiere una investigación de la vivencia de los diferentes actores con objeto de descubrir los significados para cada caso y las diferencias entre concepciones que, por desconocimiento de las "otros versiones", dificultan una experiencia, ya de por sí, suficientemente dura. Evidentemente, este sólo es el paso previo y de hecho, la "identificación de las dificultades que puedan ser corregidas" y de los "puntos fuertes que ayuden a soportar la experiencia", debería seguirse de las acciones de mejora correspondientes.

\section{Así pues, los objetivos del trabajo son:}

- Análisis de la experiencia de las personas implicadas en un ingreso en UCI.

- Detección de puntos fuertes que ayuden a soportar la experiencia

- Detección de dificultades que puedan ser corregidas.

\section{METODOLOGÍA}

Se ha utilizado el método etnográfico, en concreto, la técnica de la entrevista en grupo. El contexto de recogida de datos, ha sido una mesa redonda con el lema "Vivir la UCI, diferentes perspectivas" . El acto se puede considerar una actividad lectiva no obligatoria de los estudios de enfermería, y abierta, por su interés, al público en general; surgió como actividad complementaria de la asignatura optativa "Cuidados de enfermería al enfermo crítico" y se organizó conjuntamente entre profesores de la escuela de la E.U.I. Rovira i Virgili y profesionales de Unidades de Cuidados Intensivos.

La organización mixta desde el ámbito sanitario y el de la enseñanza, proporcionaba a los organizadores múltiples contactos relacionados con el tema, aún así, la elección no fue fácil. Haciendo un repaso de los posibles candidatos se pensó en Jaume como enfermo, por su ingreso relativamente reciente, por haber estado consciente durante toda su estancia en la unidad y por su talante reflexivo. Como familiar, Marta que había pasado alrededor de 2 meses y medio lejos de su casa, cuidando de su compañero ingresado en UCI. Marta, que en todo este tiempo, hizo de la sala de espera su hogar y de las enfermeras su familia, nos pareció que podía aportar un testimonio valiosísimo. Finalmente, con respecto a las enfermeras, María y Carmen, ambas enfermeras de UCI con más de 5 años de experiencia en la unidad, profesionalmente inquietas y bastante críticas con el entorno y el propio trabajo. Carmen, además, podía ofrecernos una doble visión por haber tenido que ejercer también como familiar de un enfermo ingresado en UCI: su padre.

Después que las personas elegidas para contar su experiencia hubieron aceptado la propuesta, se les proporcionó un guión como guía de los aspectos a tratar, con el propósito de que iniciaran la reflexión que iba a guiar su exposición. El guión, abierto y de carácter orientativo, pedía al paciente y familiares:

- Reflexión sobre la vivencia personal de la situación.

- Relato de la experiencia.

- Aspectos más difíciles de la experiencia.

- Aspectos positivos.

- Sugerencias a los futuros profesionales.

\section{Se pidió a los profesionales:}

- Reflexión sobre qué representa trabajar de enfermera en una UCI

- Aspectos que hacen de la UCI un servicio atractivo para trabajar.

- Aspectos que dificultan el trabajo en una UCI.

- Sugerencias a los futuros profesionales.

Para acabar de contextualizar el trabajo, es necesario precisar que todas las experiencias apor- 
muy graves y a punto de morirse y tú crees que este no es tu caso, pero bueno... este es un problema más que se te presenta. Empieza un desfile de médicos, todos te pasan pruebas, tú vas preguntando... no te acaban de decir exactamente qué está pasando, pero bueno... tú ves que la cosa es delicada y las primeras horas son las más dificiles porque se te hace todo una montaña

\section{Marta:}

Yo no sabía qué era una UCI, el día anterior nosotros estábamos escalando, bueno... teníamos otros proyectos, y de repente te dicen que está en la UCI, que está muy grave y que en cualquiera momento se puede acabar, o sea... este fue el diagnóstico, tenía un traumatismo pulmonar -una contusión pulmonar, corrigen los profesionales de la mesa-, una contusión pulmonar... esto que ha dicho él, yo soy maestra, pero no soy maestra de enfermería, yo siempre he estado con niños y de medicina no sé nada. Te vienen un montón de cosas a la cabeza, porque yo a las 8 de la tarde estaba en una UCI a $110 \mathrm{Km}$. de mi casa, no tenía dónde ir y con la amenaza de que en cualquiera momento se puede "acabar". Yo lo veía por una ventanilla, no lo podía tocar... y la verdad... no sé si es egoísmo o qué, pero ya me iba bien, porque pensaba... no estoy preparada para entrar dentro, porque pensaba... si lo ves por una ventanilla $y$ todo se acaba... Yo, la sensación que tengo es de desorientación total. Pienso que en aquellos momentos, el que la sala de espera permaneciese abierta las 24 horas me ayudó muchísimo. Yo no sabía dónde ir, me encontré sola y sin saber... yo no había visto una UCI en mi vida, no sabía que había horarios de visita, no sabía qué tenía que hacer.

\section{Carmen:}

Es muy fuerte ya como familiar que tu padre ingrese en el hospital, pero todavía es más duro verlo precisamente en el box $n /^{\circ} 4$ dónde cantidad de veces has visto a otros pacientes, que, la verdad sea dicha, ahora no recuerdo el nombre de casi ninguno de ellos, pero en este momento era tu padre quien estaba allí. Evidentemente yo estaba muy tranquila porque sabía con quién estaba mi padre, sabia que mis compañeras eran buenas profesionales, sabía que los médicos que le atendian también lo eran, lo que pasa... que como enfermera, y más como enfermera de UCI, sabía todas las complicaciones que podía traer un caso de ángor.

\section{Las cosas por su nombre... \\ Jaume:}

Lo único que creo que falta, al menos en el caso de enfermos como yo que están conscientes, es que los médicos te hablen claramente, porque te hablan un poco en su idioma y los enfermos no entendemos este idioma y entonces te empiezan a hablar de los síntomas y de todas las cosas y tienes que ir tirándoles de la lengua, porque sino no te acaban de hablar claro.

\section{Marta:}

A los 10 días ya me había hecho mi propia valoración de qué médico sabía escuchar más y de qué médico podía escuchar menos y yo, cuando sabía que había determinado médico, entraba porque tenía que entrar, pero la información la buscaba en otro lado. Había médicos mucho más duros a la hora de decirte las cosas y había médicos que aún diciéndote la verdad -que estaba muy malsabían suavizarla, ¿no? Entonces tú te haces una barrera, quieres oír que la cosa sale adelante. Yo, con ella -refiriéndose a una de las organizadoras de la mesa, antigua compañera de escuela de la Marta con quien se reencontró a raíz del ingreso y con quien, también a raíz del accidente, estableció una duradera amistad-tuve muchas charlas fuera de la UCI y una cosa que agradeceré siempre es que ella nunca me dijo que todo saldría bien, o sea... nunca me dijo: Javier está bien. Me ayudó a no crear falsas expectativas y a afrontar una realidad que yo veía, pero no quería aceptar. Intenté entrar en la UCI, o sea... intentaba que me explicaran el máximo posible. Yo, cada palabra que me decían, me la apuntaba y al final me sabía neumotórax y no se qué y no sé cuantos, me sabía el vocabulario... y cómo funcionaban los aparatos.

\section{Carmen:}

$Y$ te dicen que harán lo que puedan... ¿Harán lo qué puedan? ¿De qué harán lo que puedan? Si es que es tu padre quien está dentro y es que le tienen que sacar un trozo de hígado. (...) Y después... 
claro, hasta que no salen y te dicen que todo ha ido bien... creo que aquí deberían informar más a menudo.

\section{Y... las cosas que no se pueden nombrar... Marta:}

Yo sabía que estaba muy grave y que"la cosa" se podía "acabar" en cualquier momento.

Quería aceptar, en el supuesto de que llegara" el momento", que no me cogiera desprevenida.

Tú pensabas que te había tocado a ti, que "la historia" se habia" acabado".

Porque tú sabías como estaba tu familiar y sabías que en cualquier momento podían abrir la puerta y... se ha" acabado".

\section{Lo más duro...}

\section{Jaume:}

Lo que más eché de menos en la UCI: Una de las cosas más importantes es poder estar acompañado, sobre todo cuando son enfermos que están conscientes las 24 horas del día, el acompañamiento del familiar llena mucho (...), durante el día no noté tanto su falta, pero por la noche cuando se van las visitas y las enfermeras no pasan tan a menudo, las horas esas que estás muy solo son muy angustiosas. A los médicos en cambio les dices esto y te dicen que hay una normativa en la UCI y no le dan importancia. Otros enfermos de la misma enfermedad con los que he hablado, también lo han echado de menos.

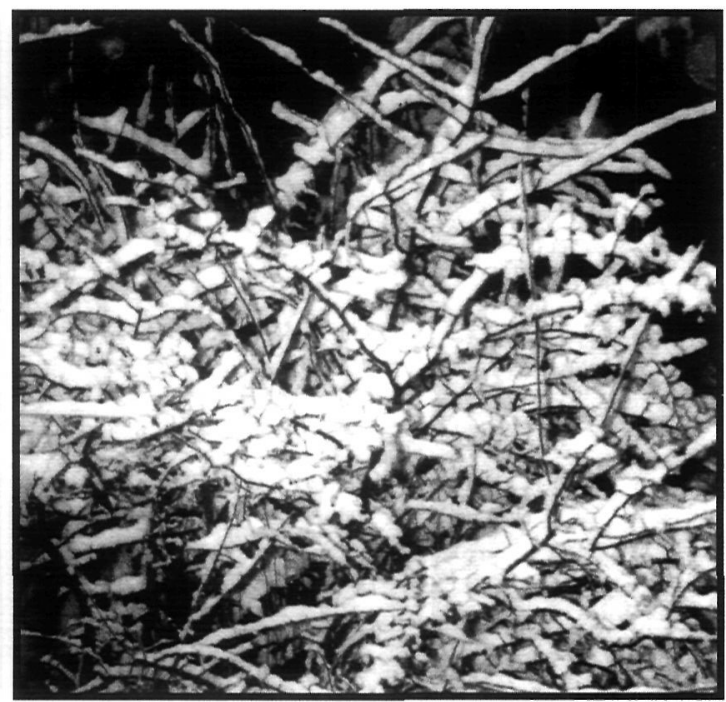

La inmovilidad es... si no se pasa no se puede contar... Yo estuve 5 o 6 días en que sólo podía mover la cabeza y una de las cosas que más agradecí es que dos.. una enfermera y una auxiliar que habían pasado por situaciones de inmovilidad y sin que yo lo pidiera, me moviesen los brazos y las piernas, porque aquello me daba un alivio... vamos, muy grande!

\section{Marta:}

Otra historia es como él quedaría del "coco", nadie sabía como quedaría, si se despertaría bien, si no se despertaría bien, si sería un vegetal, si no sería un vegetal... Otra cosa que yo recuerdo con mucha, muchísima angustia, es el hecho de las visitas que -supongo que para el personal de enfermería son rutinarias- pero para mí, lo más angustioso es que si te decian a las 8 abrieran a las 8 y 10 , porque esto quería decir o que algo andaba mal o que alguien había muerto, entonces para mí... cada visita en que se retrasaban yo pensaba... eres tú. Si pasaba algo, te lo decían con mucha delicadeza, con un tacto exquisito pero... yo sólo pedía que sí decían a las 8 , si podian abrir a las 8 menos 3 minutos mucho mejor. El día que abrian a las 8 y cuarto, en este cuarto de hora pasaban 10 años de mi vida, porque tú sabías como estaba tu familiar y sabias que en cualquiera momento podían abrir la puerta y... se ha acabado. (...) ¿Qué encontré a faltar?... yo pienso que junto a los hospitales debería de haber unos hoteles preparados para gente así, te encuentras que no sabes dónde ir, y ahora imaginaos que me llegan a cerrar la UCI.

\section{Carmen:}

Aquí viene la verdadera reflexión como familiar, porque aquí ya dejas de ser enfermera, a ver... dejar de ser enfermera... no lo puedes dejar de ser nunca, lo que pasa es que allí ya no es tan fácil, ¿no? Yo no podría quejarme nunca, ni nunca en la vida diré que las enfermeras de allí no son profesionales, al contrario, lo son iy mucho! Lo que pasa...es que... alli haces de verdadera familia, allí es cuando estás en la sala de espera 4, 5, 6 horas que duró la intervención quirúrgica sin que nadie te diga nada. Entonces es cuando yo empecé a pensar si era así como se sentían las familias que 
yo trataba en la unidad como enfermera y verdaderamente pensé que sí era así, era muy duro, era muy duro reconocer que por el hecho de que yo no saliera a decirles que estaba durmiendo, o que estaba bien, o que estaba tranquilo, o que necesitaba un bolígrafo, o que... la familia se angustiara tanto. Aquellas horas fueron verdaderamente interminables, y... tu familia la información la busca igual y está acostumbrada a que seas tú quien se la de, porque tú eres enfermera. Lo que encontré más a faltar y lo que me costó más de pasar es el hecho de tener que estar tan lejos de mi padre el día anterior a la intervención quirúrgica, el hecho de tener que continuar trabajando, justamente trabajaba en un hospital y yo sabía que mi padre estaba solo en otro hospital.

\section{Maria:}

La UCI puede ser, no tiene porque serlo necesariamente, pero puede ser un espejo de nuestra vida, alli pasan muchas cosas que te hacen reflexionar y te dicen que no estás nunca a salvo de nada, no estás nunca protegido, que cualquier día puede pasarte a ti, esto, y esto nos da miedo. A mí, personalmente, me da miedo. Para mí lo que es muy difícil es que hay mucho sufrimiento, y no me refiero al sufrimiento fisico, que también lo hay, pero sabemos como afrontarlo, los profesionales saben cómo manejar el sufrimiento físico. Pero hay otra clase de sufrimiento: hay personas jóvenes ingresadas de repente, personas que ayer llevaban una vida normal y al día siguiente están allí, en una cama, imposibilitados; personas que no saben qué pasará con su vida, si sobrevivirán, cómo quedaran... hay familiares que sufren tanto como el enfermo... me refiero a este sufrimiento, ¿no? a esta angustia por qué pasará.... esto es muy dificil. Y este sufrimiento de las familias no se puede comparar al que sentimos nosotros, son incomparables, pero este sufrimiento es como una gota de agua que va erosionando. Hay otras cosas igualmente duras, en un principio todo el mundo que ingresa en una UCI, ingresa porque tiene posibilidades de salir adelante (...) pero algunas veces, esta lucha por sobrevivir es muy dura, dura mucho tiempo, exige mucho esfuerzo a la familia, al personal, al enfermo y aun así, algunas veces, la persona acaba muriendo y esto, con todo el esfuerzo que hay detrás, genera, en el personal, frustración, genera impotencia, genera tristeza. En la UCI, lo diré como una de las cosas agradables, se crean lazos afectivos, y esto es bueno, pero estos lazos que se crean, cuando un enfermo se te muere, cuando dejas a una familia... también nosotros lo padecemos, es una pérdida por la que pasamos, una pérdida que nos causa un sufrimiento, una pérdida que nos entristece...

\section{Y... las cosas buenas, que también las hay Jaume:}

Los aspectos positivos de la desgracia que es pasar por la UCI es que te das cuenta de las personas y los amigos que tienes y sobre todo, un aspecto muy importante, es la familia. La familia... sí estás bien con tu mujer y los hijos es muy importante porqué son los que te hacen ver que estás pasando por una situación transitoria y que con la ayuda de todos hay que salir adelante. Insistiré en el hecho porque cuando me dijo el médico que me podría pasar 6 meses ingresado como otros casos que habia habido, se te hace todo una montaña y es un poco desesperante cuando sólo hace 24 horas que estás ingresado y ya se te hace pesado, que encima te digan que en aquella situación te puedes pasar 6, 7, 8 meses o el tiempo que sea. También se aprende mucho a valorar la vida, té das cuenta, cuando te falta la salud, que la salud es el factor más importante que tenemos en esta vida. Aprendes a valorar otras cosas de la vida. A veces, ves que hay estas peleas profesionales -todo

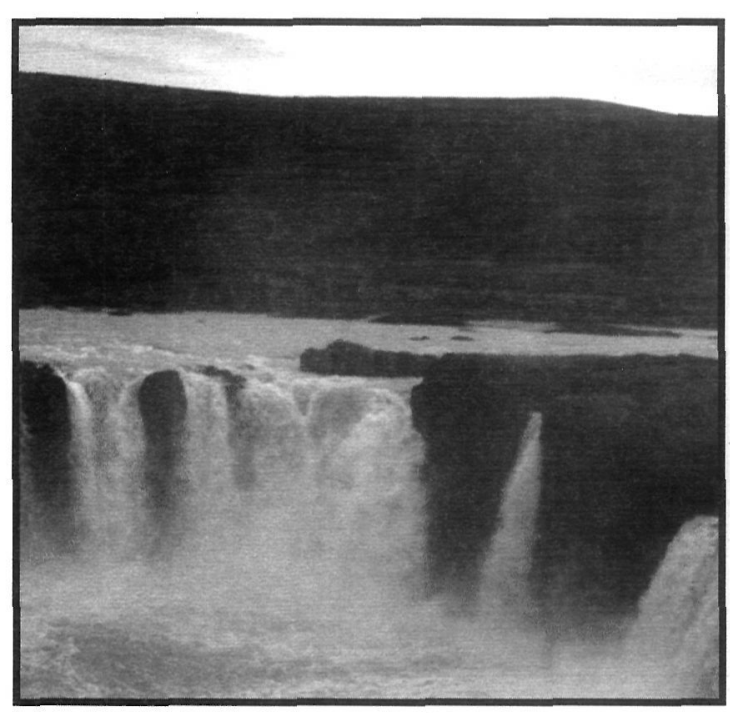


el mundo tenemos que tener, supongo, una ambición profesional para salir adelante- pero ves gente que se hacen la "trabeta" unos a otros para poder ascender y te das cuenta que esto no te lleva a nada, porque si no tienes salud: ni tienes trabajo ni tienes nada.

\section{Marta:}

Yo siempre he dicho que a mí la UCI me creó una dependencia brutal. Yo, al final de la estancia en UCI, entraba dentro y pasaba trabajos a máquina de las enfermeras, o sea... fue una relación muy estrecha, porque yo necesitaba sentir que alguien estaba conmigo, porque yo no tenía a nadie. Me acuerdo que el día de la "mona" otra señora y yo fuimos a comprar "monas" para todos los de la UCI, porque ellos eran el único vínculo que teníamos allí, ellos eran las personas a quien queríamos. Otra cosa que recuerdo mucho de la UCI es que después yo no quería marchar, ni él ni yo, estábamos muy bien, estábamos muy... arropados. Yo sólo le decía al Dr. R. "¿No podemos esperar un poco más? Ya bajaremos... no es necesario ir tan rápido, si hay camas podemos seguir aqui" (...) yo me pasaba horas y horas con él, tenía el apoyo de todos, me tomaba el cafelito con ellos... (...) y el día que bajamos a planta, jlos dos, eh! lo pasamos muy mal. Yo siempre he dicho que creé una adicción, una adicción a la UCI. Yo pienso que en este caso fue una UCI muy humanizada y de la que guardo un buen recuerdo.

\section{Carmen:}

El otro día intentaba yo hablar con él sobre este tema y yo le decía: pero papá, ¿tú nunca te sentiste solo en la unidad? Y él me decía que no, que consideraba que las enfermeras siempre estaban de guardia, siempre se estaban preocupando por él. E incluso yo le hice una pregunta un poco intencionada: ¿Y tú no crees que esto era porque eras mi padre? Y me dijo que no, que él veía como ellas trabajaban todo el tiempo también con los otros pacientes.

\section{Maria:}

Me gusta trabajar en la UCI, porque hay un equipo de gente, y me refiero a todo el mundo, eh..., hay un equipo de gente que está muy sensibi- lizado por el sufrimiento, muy sensibilizado quiere decir que es receptivo, que se trata de personas sensibles que saben ser próximas a los otros y... que sienten también, salvando las distancias, claro, y... me gustaría decir... malo el día que no sintamos este pequeño sufrimiento, y el día que perdamos esta sensibilidad, porque entonces quizás convendrá que nos replanteemos nuestra vida, que nos planteemos descansar, que a veces uno se cansa también, o dedicarnos a otra cosa. Yo diría que hay un equipo de profesionales que son sensibles al sufrimiento y que están preparados, humana y técnicamente para hacerle frente, para plantarle cara. Y esto es una de las cosas que me gustan... el espaldarazo que tengo. Lo mejor de la UCI es la recompensa, el enfermo milagro... o no... -dice riéndose-. El enfermo que ingresa con pocas esperanzas, que dices... ostras, éste no aguantará, qué difícil lo tiene... y pasan los días y tu te dejas la piel, y todo el mundo está allí metido y... y llega un día en que te vuelve aquel enfermo, ¿no? Que viene a verte. Que está bien. Que se ha curado... Mira, Jaume es uno de ellos... bueno...como él muchísimos. Te vienen a ver porque tienen ganas de verte, de que los veas... yo creo que no lo hacen por cumplido, quieren venir, vienen a agradecerte y a decirte que han estado bien cuidados, que se han sentido bien tratados, bien atendidos, que están contentos, que tu formas parte de ese éxito... a ver... uno no puede estar contento de haber tenido que pasar por una experiencia así, pero... están vivos y están bien y esto es un motivo de alegría para ellos y vienen a darte las gracias. Para mí esta es la mejor recompensa.

\section{Las cosas que ayudan... \\ Jaume:}

Te ayuda la familia, sobre todo la mujer, que es a quién tienes más cerca, te hace ver que tienes que salir adelante, pero también el personal que hay en la UCI, tanto médicos, como enfermeras, como auxiliares, todo el personal de la UCI te ayuda mucho a tirar adelante y ves lo positivo y no ves lo negativo. Para el estado de ánimo, el entorno familiar es lo más importante, porque desde el mes de mayo que estuve ingresado y después de que sali de la clínica, he estado hablando con otros enfermos del tratamiento del Guillain Barré y sé 
que algunos no lo han asumido tan bien porque su entorno familiar no era el adecuado para conseguir esta fuerza y este ánimo para salir adelante. También valoras mucho ver que los demás se ocupan de ti. Yo recuerdo que las 4 veces que dejaban entrar a la familia me decían: "fuera está éste y el otro y el otro..." y yo siempre preguntaba quién había fuera, te llena mucho ver que mucha gente se preocupa por ti en esta situación y realmente es muy importante. Otro factor que ya he dicho antes es todo el equipo médico que hay en la UCI-no es porque esté ella aquí delante- (ella es enfermera), el trato del personal ayuda mucho al enfermo porque estás todo el día con ellos. Otra cosa que te ayuda mucho son las ganas de vivir porque piensas que siempre puede haber enfermedades y gente que están mucho peor que tú, entonces esto también te da ánimos para salir adelante. También, aunque sea una cosa difícil de entender para los que no son practicantes, me di cuenta que rezar, sobre todo por la noche que son horas de mucha soledad, - y yo, no soy nada practicante- te ayuda a llenar este hueco y estas horas que cuestan de pasar.

\section{Marta:}

Yo siempre agradeceré esto: que la UCI estuviese abierta, que el personal fuese lo suficientemente inteligente como para no echarte de allí a las 10 de la noche. Coincidimos con una señora que estaba en la misma situación con su marido con otra enfermedad y alli teníamos el saco de dormir, teníamos el neceser y así íbamos tirando (...) yo no tenía ningún otro sitio a donde ir.

\section{Carmen:}

Tu familia lo tiene un poco más fácil, fácil en el sentido de que, información, tiene... la que le toca y aparte la tuya. Nosotros, evidentemente, no teníamos ningún problema para entrar, salir, llamar por teléfono, pedir información, etc... lo teníamos todo muy fácil.

\section{Maria:}

¿Como lo hacemos para hacer frente a este sufrimiento? Probablemente nos lo hacemos de muchas maneras y muchas ya son como muy automáticas, el otro día, pensando, se me ocurrieron tres cosas que me ayudan a auyentar estos demo- nios, ¿ no?, estos dramas que... que hay y que un poco se contagian, ¿no? ¿Como lo hacemos? Hablando. Se comenta con todo el equipo... se comentan muchas cosas, se comentan muchas dudas, se comentan los sentimientos que uno tiene, las angustias... (...) Esta es una manera de sacudirse de encima todo esto que... que es difícil, ¿no? Después... se ríe mucho, en los hospitales...-algunas veces se ríe demasiado-pero... yo creo que reírse y tener un momento para desconectar un poco, en el lugar adecuado y en el momento adecuado es bueno. Te ayuda a cargar pilas para después volver a estar en tu sitio y volver a estar entera y dispuesta y entregada a lo que haga falta. Yo siempre digo que se ríe mucho y pienso que está bien, pero hay que hacerlo bien, eh, quiero decir... sin dañar a nadie, ¿no? Otras veces también se llora, hay situaciones que, por lo que sea te enganchan, ¿no? Y ya he dicho que el dolor que tú puedes sentir en aquel momento no se puede ni comparar al dolor que sienten los enfermos, al dolor que sienten los familiares, pero hay situaciones que emocionalmente te desbordan y tienes que coger y largarte de allí en aquel momento e irte $y$ purgar todo esto, y... lloras, claro que sí.

\section{Los vínculos... \\ Marta:}

Hubo otro día que hizo un cambio espectacular, hacia bien, pero salió el médico a quien yo tenía confianza con una cara seria, para decirme que estaba mejor, pero salía con cara seria, y cuando me dijo que estaba mejor... yo no sabia dónde ponerme... bueno... alegrías, abrazos... unas cosas que ahora las piensas y dices... imadre mía!

Pero claro está... necesitas un hilo, necesitas un vínculo con esta gente porque son ellos los que están con tu familiar y tú sólo puedes esperar, esperar, esperar y esperar... y tú no tienes nada en tus manos como para decir... ¿qué haces?

Yo, lo que necesitaba en aquellos momentos en que te encuentras sola, lejos de casa, es alguien que te eche un cable $y$ aparte de enfermera sea amiga, ya digo... yo encontré a dos médicos, encontré a Maria...

La relación que se crea entre las familias es tan grande, tan grande... que acabas que acabas queriendo al familiar, al padre, al marido o al hijo de 
aquella persona. Sufres por ellos por que ves que son las personas con las cuales tú tienes relación en estos momentos, la persona que te está ayudando, la que está sufriendo contigo. Yo diría que hay dos equipos, el de dentro y el de fuera.

\section{Maria:}

¿Cosas buenas de la UCI...? Esto que decía de los vínculos, se da un trato muy estrecho con los enfermos, con los familiares, y se crean vínculos... cada enfermo, cada familia es una relación diferente, evidentemente, yo esto lo valoro como bueno, porque esto me hace sentir más próxima a aquella persona con la cual yo tengo una relación, profesional, ya lo sé, pero me permite acercarme un poco más

\section{Ni buenas ni malas... cosas que pasan...}

\section{Jaume:}

Nunca en la vida me habría imaginado que el celador fuese un peso pesado tan importante en el organigrama de un hospital, yo pensaba que el más importante era el médico, pero el médico una vez te ha dado el tratamiento para la enfermedad... pero a mí, si no venían los celadores no habia quien me moviera y yo los esperaba como agua de mayo.

\section{Marta:}

Intenté humanizar la sala de espera. O sea... todos los temores que yo había tenido... intentaba que los que llegaban nuevos no sufrieran tanto. Recuerdo el caso de un chico gitano que con 16 años perdió a su madre - son personas muy impulsivas- yo me lo encontré a punto de tirarse por la ventana de un quinto piso. Lo cogí, nos sentamos y pasamos tres horas hablando -el con su madre muerta dentro, yo con Javier que ... bueno, en cualquier momento podía tocarme a mí-. Yo no sé si pude ayudarle o no, pero como mínimo tuvo un apoyo. La prueba es que después de 8 años aún seguimos viéndonos ¿no?

\section{Maria:}

Hay una cosa que yo llamo la trampa de las UCI y que... las UCIs ya sabéis: son monitores, respiradores, bombas que piten, campanas, luces... hay muchos aparatos, mucha técnica, un enfermo que está muy grave, a quien hay que hacer muchas cosas. A veces, esto es una trampa. Estos monitores, estos pitos, estas campanas, estas luces... te hacen olvidar que detrás de todo esto hay una persona. Algunas veces el enfermo no se puede comunicar contigo -aunque tú sí que puedes comunicarte con él, eh- y... esto a mí me ha pasado y yo creo que os pasará a todos, pero... desde aquí damos el primer paso para que esto no pase. Hay que hacer un esfuerzo consciente, a mí me ha pasado... un dia alli enfrascada entre bombas, monitores y pitos, de pronto... descubrir la mirada del señor que está intubado que no puede hablar y que me está buscando. iY yo me siento fatal cuando pasa esto! Porque.. yo pienso que como profesional no puedo esperar a que él me busque, sino que debo ir yo a su encuentro, ¿no? Y este es el esfuerzo consciente: recordar cada día a cada momento que detrás de todo esto hay una persona que puede necesitar algo, que puede buscarme, que quiere saber que tiene alguien a su lado, ¿ no?

\section{Los consejos...}

\section{Jaume:}

En general no tengo nada que decir de las enfermeras, pero como todas los trabajos siempre hay personal más profesional y otro menos profesional. Sobre todo el tema de que yo era incapaz por mi mismo de hacer mis necesidades fisiológicas, no me podía mover, a duras penas podía hablar; cuando te traían la botella había quién te la dejaba de cualquiera manera, y esto ya de por si es un poco humillante -quizás humillante no es la palabra-pero ya de por sí es duro tener que pedir a una persona que te ayude en estas necesidades... y esto son cosas que se pueden hacer de muchas maneras. Habia otras compañeras que lo hacían con mucha delicadeza... como sí fuese la cosa más normal del mundo, en cambio otros... Después otra cosa que quizás ellas no saben... como que la mayor parte de enfermos que están en la UCI son enfermos que no están conscientes, comentarios que a veces hacen de otros enfermos... es como si yo en mi trabajo -yo trabajo en un banco-ante un cliente hiciese un comentario del cliente que se acaba de ir. Puede que sean comentarios sin trascendencia... pero en aquel momento piensas... no sé... no son agradables. Sólo os querría decir que si algún día estáis en una UCI, una 
sonrisa, cualquier detalle, por pequeño que sea, el enfermo en aquel momento os lo agradece. Yo tengo una anécdota con la mujer de la limpieza que pasaba cada día 2 o 3 veces a barrer y yo le dije: escuche, tengo unas ganas locas de ayudarla a pasar la escoba -yo, la escoba, no la he tocado en la vida- ;Y el día que me fui a despedir, me la dio, la escoba!

\section{Marta:}

Yo lo único que os diría es esto, que de cara al familiar yo pienso que es superimportante la humanización.

\section{Carmen:}

Yo creo que enfermería, con la familia, tiene mucho que hacer. Los médicos tienen su parte médica y es muy importante el hecho de que el médico salga y dé el parte médico pero la familia también quiere saber sí descansa, si está tranquilo si no tiene dolor... enfermería tiene que crear su propio espacio para informar a las familias y debe acercarse mucho más a ellas. Yo, a partir de aquí cambié, tampoco se puede decir que soy la enfermera ideal ni la enfermera perfecta, lo que pasa es que te das cuenta que queda mucho trabajo por hacer aquí, mucho trabajo de salir a las familias y de estar con ellos: a informarlos, a abrazarlos, a... a ayudarlos en lo que puedas. Dedicarte a las familias quiere decir dedicarles una parte de tu tiempo (...) esto supone trabajo para la enfermera aparte de la que ya tiene con el paciente, pero es muy importante el hecho de que las enfermeras, esto, lo podamos llevar a término.

\section{Maria:}

Queria hablar de nuestro trabajo con las familias, en el sentido que el enfermo que de pronto, porque muchas veces un ingreso en una UCI es una cosa repentina, ¿no?, de pronto se ve separado de su vida, de su medio, de su familia y se encuentra en un ambiente extraño y además en una situación crítica... para su familia y... la familia, a veces, es el único vínculo que él puede mantener con su vida anterior, ¿no? Y nosotros debemos utilizar a esta familia... utilizarla entre comillas, quiero decir... la familia tiene que sernos útil, a nosotros y al enfermo, porque... tenemos un objeti- vo común. ¿Pero... utilizarla cómo? Hay que conseguir que este lazo que es muy débil, como un hilo muy fino, el enfermo lo viva como una cadena pesada, si hace falta, como una fuerza poderosa que le ata a la vida. A veces la familia puede ser único incentivo que tiene este enfermo para... para salir adelante. $Y$ digo que debemos utilizarla porque yo he visto muchas veces... nosotros debemos enseñar a la familia a estar con el enfermo que está en una UCI, yo he visto muchas veces familiares parados en la puerta... bueno... con una cara de asustados mirando los monitores, los respiraderos... aterrorizados, ¿no? Y les he tenido que decir: ¡Pase! ¡Pase! Tóquelo, dele un beso, abrácelo, dígale que está aquí, que... - no le pida cosas... porque... a veces piden cosas y el enfermo igual los oye pero no puede contestar - $Y$ te dicen... ¿Y lo puedo tocar? ¡Ya lo creo que sí!... y no es que lo pueda tocar, es que debe tocarlo! Es que es bueno para él, que le toque! Y este es un trabajo que debemos hacer con las familias, lo debemos hacer para puedan sentirse útiles, para que puedan seguir con la relación -dentro de las limitaciones que va a tener esta relación- pero así podrán seguir en contacto con su familiar y... y yo creo que esto es bueno para el enfermo, ¿no? Porqué... te ayuda, tener a alguien... alguien a tu lado que te pide que salgas adelante, ¿no? y que te está esperando.

Todo es justificable... no quiere decir que sea fácilmente soportable... fácilmente llevable, ¿no? Pero que todo es justificable, todas las cosas que dicen los enfermos, todas las cosas que hacen... todas se pueden entender, itodas! Yo entiendo a la familia que se quiere colar pese a que hay unas normas, porque yo también me querría colar, claro que sí, porque yo querría ver a mi familiar, y entiendo al señor a quién acabas de hacer el cambio postural y a la hora ya necesita que lo cambies otra vez... porque es lógico, si es que no puede moverse, yo en la cama me muevo cuando me da la gana y... aún así me canso, y... yo que sé... el chiquito que llama constantemente al timbre y que... te dice que no sabe qué le pasa, que ya no tiene dolor pero que no sabe lo que quiere, que está muy solo... Se puede entender todo... yo creo ¿no? Porque... es una situación muy dura... yo creo que tenemos que hacer este esfuerzo para entenderlo 
todo y para modificar nuestras energías en el sentido que no nos enganchamos con peleas con los familiares, que si esta no es la hora, que si no sé qué, que hay unas normas... que... sino.... suavizarlo todo un poco y ser más... ser más... más empáticos, ponerse a la piel del otro y ya está, entonces es fácil entenderlo todo.

\section{CONCLUSIONES}

$\mathrm{El}$ ingreso en una UCI, que en la introducción se tildaba de "experiencia singular", se ha revelado como una experiencia muy dura, a menudo traumática -se apuntaba también en la introducción-, una experiencia que puede dejar secuelas y no sólo físicas. Y se ha revelado como una experiencia dura, difícil, cruda; no sólo para los enfermos ingresados, sino también para todos los que de una u otra forma se ven involucrados. También ha quedado claro que los profesionales, aún desde el distanciamiento que ofrece el conocimiento del medio y la relación profesional, también sufren. En este sentido, sería interesante contrastar el sentimiento expresado por los profesionales en su testimonio, con la idea que desde fuera se puede tener del sentimiento que experimenten estos profesionales, habituados a la muerte y al sufrimiento... pero no tanto. Parece que puede haber un prejuicio que haga pensar que el contacto continuado con estas situaciones críticas anestesian los sentimientos de las personas.

El tema recurrente de la sanidad y la información, la comunicación de los profesionales con los clientes, la comunicación efectiva -sería necesario decir-, ha vuelto a salir como no podría ser de otra manera. Esta es una asignatura pendiente de la sanidad y seguramente también de otros ámbitos. Hay que preguntarse... ¿Qué se esconde detrás de este lenguaje críptico que dice y no dice...? Evidentemente, los adelantos científico/técnicos generan un lenguaje propio, cambiante y cada vez más especializado, pero esta no es excusa para hacer de la información un jeroglífico, justamente lo contrario de lo que debería ser.

Siguiendo con el lenguaje, tampoco deberían sorprendernos los eufemismos que Marta utiliza para hablar de la muerte: "la cosa, acabar, llegar el momento, acabarse la historia"... ahora bien, curiosamente habla claro cuando se refiere a la muerte de otro alguien que no es su familiar, lo cual demuestra que el vínculo afectivo distorsiona la percepción de las cosas y evidencia también la presencia constante del miedo a la muerte.

Es curioso, -o no...- que pese al elevado grado de tecnificación de las UCIs, se haga, desde todos los frentes, una constante apelación a la humanización. El dominio de los aparatos, de los tratamientos sofisticados y de las últimas tecnologías aplicadas a la sanidad se da por supuesto y forma parte de los requisitos mínimos de profesionalidad.

Totalmente de acuerdo hasta aquí... ahora bien...

- ¿Por qué la humanización, tan necesaria según se ha podido ver, parece que es considerada una característica ajena a la profesionalidad y que depende más de la buena voluntad del profesional y de sus características personales que de la exigencia profesional?

- ¿La carga de trabajo añadida que representa el cuidado de la familia y esta dedicación a las personas, además del aspecto tecnológico y puramente biológico, es tenida en cuenta por la administración?

- ¿Forma parte de la exigencia de las direcciones de centros y está contemplada en la planificación de recursos?

No se puede decir que la familia se haya revelado como un agente terapéutico esencial en el cuidado y tratamiento del enfermo ingresado en UCI, porque no es ninguna revelación. Hasta ahora, y en nuestro medio cultural, hay acuerdo en el papel crucial que representa la institución familiar en el apoyo a las situaciones críticas y de hecho, los testimonios aportados no hacen más que validar esta opinión. La familia, pero, padece un desgaste y está sometida a un padecimiento que debe ser contemplado también desde el punto de vista sanitario, de manera que debe incorporarse como un objetivo más en la planificación de los cuidados los cuales deberían incluir aspectos como la enseñanza en relación al cuidado del familiar y al propio autocuidado, aspectos de apoyo emocional a los familiares o agentes recurso así como ayuda en las modificaciones ambientales que faciliten la estancia. En este sentido, es importante tener presente los lazos de solidaridad que se establecen entre las diferentes familias y la utilización terapéutica de 
los mismos en su cuidado, así como la consideración de la "sala de espera" como un recurso material valioso que merece nuestra atención.

La gran cantidad de normas que rigen la unidad ha salido también en el relato. Ahora bien, en algún caso se ha cuestionado, sobre todo por lo que respecta al régimen de visitas, que hasta ahora es limitado en horario y personal.

El enfoque múltiple de la experiencia evidencia una diferente consideración para un mismo hecho según quién lo valore. Así pues, la rigidez de las normas o "pequeñas" transgresiones en el cumplimiento del horario de visitas son consideradas por unos, los profesionales, como cuestiones secundarias y en ningún caso vitales, mientras que para los familiares son fuente de angustia y sufrimiento. Convendría en este sentido estudiar más profundamente cuáles son las diferencias en la consideración de los hechos y conciliar, en la medida de lo posible, las diferentes posturas. La diferente consideración otorgada por los diferentes actores a un mismo hecho es, de manera inmediata, el principal valor profesional conseguido a partir de la realización del trabajo, en tanto en cuanto una muy pequeña y sencilla modificación de las actitudes profesionales puede traducirse en una importante mejora de la atención.

También a nivel profesional, pero ya a más largo plazo, el trabajo realizado aporta un primer contacto con un método de investigación que se ha mostrado útil en un medio dónde, hasta ahora, parece que sólo contaban los métodos cuantitativos, con un prejuicio evidente hacia la investigación cualitativa. El trabajo de campo se desvela como una herramienta útil en la realidad, si va acompañada de acciones de mejora guiadas por las conclusiones. Es necesaria, pues, la voluntad de actuar, además de la de investigar.

Destacar la capacidad de las personas para encontrar, si se quiere, una consideración positiva a una experiencia tan traumática como pueden ser el paso por una situación crítica e ingreso en una UCI.

Destacar también el valor de los consejos aportados por los protagonistas que enfatizan la importancia de la dignidad en los cuidados, el respeto, la humanización, la empatía y, de nuevo, la familia y su cuidado.
La aportación de testimonios reales se muestra útil como recurso docente en tanto en cuanto consigue la participación de gran cantidad de alumnos y profesionales en una actividad de asistencia no obligatoria y su colaboración activa en el coloquio posterior. Se trata por tanto de una actividad que ha despertado interés e incitado a la reflexión de alumnos y profesionales.

$\mathrm{El}$ análisis minucioso del material vivifica una sensación que en su día pasó más desapercibida, menos intensa, más desapasionada: la emoción. El material obtenido debe juzgarse como muy valioso por tratarse de un testimonio de carácter íntimo y por el esfuerzo que representa hurgar en antiguas heridas con un ánimo de crítica constructiva. El hecho del conocimiento previo del campo por parte de los investigadores ha hecho que la participación de los protagonistas haya sido excelente, no tanto por lo que dicen -esto es libre y forma parte de la investigación- sino por como lo hacen: con colaboración, entusiasmo y espíritu crítico.

\section{BIBLIOGRAFÍA}

- Allué, M. (1996) Perder la piel. Planeta / Seix Barral, Barcelona.

- Prat, J. (1997) El estigma del extraño. Ariel, Barcelona

- Karin T. et al. Nurses' beliefs and attitudes toward visiting in adult critical care settings. American Journal of Critical Care. Volume $2 \mathrm{~N}^{\circ} 3$; 238-245.

- Marco Landa, I. et al. (2000) Creencias i actitudes de las enfermera de cuidados intensivos sobre el efecto que la visita abierta produce en el paciente, familia y enfermeras. Enfermería Intensiva; 11(3) 107-117

- Taylor, S. i Bogdan R.(1992) Introducción a los métodos cualitativos de investigación. Paidos, Barcelona

- Van Servellen G. i Leake B. (1993) Burn-out in hospital nurses: a comparaison of acquired immunodeficiency syndrome, oncology, general medical, and intensive care unit nurse samples. Journal of Professional Nursing. 9 (3) : 169-77, May-Jun. 